\title{
ENCOURAGING EMPATHY IN ENGINEERING DESIGN
}

\author{
Holly R. Algra and Clifton R. Johnston \\ Dalhousie University \\ Holly.Algra@dal.ca and Clifton.Johnston@dal.ca
}

\begin{abstract}
-
Empathy is imperative for the creation of user-friendly products, and can be both taught and learned according to Jon Kolko in his book, "Well-Designed". In it, he suggests that successful design requires the integration of human factors and an empathy with the users. However, in such statements as "the left circle is engineering, the right circle is design" and "engineering is a reductive activity... design, however, is frequently a generative activity" seem to imply that engineering does not overlap with design. Section headings including "Motivating Engineers", and "How do you bridge the ...gap between engineers and designers?" also strengthen the idea that engineering and design are not performed by the same people. Much of the literature on human factors implies that engineers are analytical, solution-oriented, and thorough. However, creativity and human considerations seem to have been left to someone else, or pushed to the end of the design process as a last-minute add-on. In this work, we focused on how to change this perception by helping engineers to better integrate human factors and empathy into their design processes.

We have been exploring potential approaches that could encourage the two seemingly disparate worlds to merge together. After an initial design project with a focus on incorporating experiential learning and human factors did not achieve the expected outcomes, it was clear that encouragement and intentions were not enough to integrate empathetic principles into engineering design. Our research included analyzing different product choices based on experience in a specific area, and a case study to identify the source of human consideration in a capstone design project. This has culminated in the idea that a tool needed to be created to help novice designers introduce human factors into the early stages of their design process.

We avoided making a checklist which could be completed with no real consideration for the user. Instead, we created a prototype of an application which we believe would help spark discussion and ideation, while interacting with designers on a platform that is accessible and recognizable. In this paper, we will describe the development activities that were required for
\end{abstract}

this tool as well as the additional work needed to create an operational application for multiple operating platforms. In addition, we will discuss how we believe this will influence the incorporation of human factors into the design processes of novice designers and in which applications we believe this will be the most useful.

Keywords: Design Tools, Engineering Education, Engineering Design, Human Factors, Human Centered Design, Empathy, Empathic Design

\section{INTRODUCTION}

Everything in use has been designed in the sense that it has been created or used deliberately to solve specific problems. It is through design that desired outcomes are achieved [16]. Engineering itself is typically characterized by solving problems, but more than simply changing one's surroundings, engineering design is realizing new possibilities by determining desirable compromises where resources are limited and needs are diverse [8][13].

While design has sometimes been viewed as outside the realm of what typically belongs in the core of an engineering curriculum, namely natural sciences and mathematics [14], it is in a unique position that bridges both art and sciences [17]. Design education is of great importance to all engineering students, even those who do not go on to careers in design [18].

\section{PROCESS}

\subsection{Engineers as Designers}

A 2009 study of the Place of Design within Ontario defines design as a creative activity that is a combination of art, business, and technology, and emphasizes that it is not simply the aesthetic factors of products, but the function, production, and consumer appeal [20]. The National Occupational Classification for Canada includes design jobs in the classifications of several engineers, including the Mechanical Engineers and 
Technologists. However, engineers are not considered as one of the design occupations in reports delving into the design industry in Canada, which includes statistics on architects, industrial, graphic, interior, and theatre designers among others.

In Kolko's book "Well-Designed" [11] statements including "the left circle is engineering, the right circle is design" and "engineering is a reductive activity... design, however, is frequently a generative activity" seem to imply that engineering does not overlap with the view of what constitutes design. Section headings including "Motivating Engineers", and "How do you bridge the ...gap between engineers and designers?" also strengthen the idea that engineering and design are not performed by the same people. This literature suggests that because engineers are analytical, solution-oriented, and thorough, with little regard for the more subjective field of human considerations that they are not considered as designers. Human focused designs are based on the idea of empathy, that understanding the users will lead to the design of innovative, usable solutions [10]. However, these human considerations seem to have been left to someone else, or pushed to the end of the design process as a last-minute add-on to engineering design.

\subsection{Bridging the Gap}

In this work, we focused on how to change this by helping engineers to better integrate human factors into their design from the beginning of their project processes. To understand how to better bridge this gap between engineers and human factor considerations, it is important to identify in which areas engineers are criticized. Engineers tend to think of design as being based in specifications and technology without a necessity for the incorporation of human considerations and human factors. As engineering schools generally focus on sciences and engineering analytical techniques [1], one explanation for the lack of consideration for the user and the humans involved may be a focus on the project at hand instead of a more complete understanding of how the specific project fits into the broader system [12]. This system may include interactions with other parts of a machine, or a humanmachine interface, or a societal, organizational or political framework into which the design must fit.

Clients often perceive that a designer will implement a previously decided solution instead of strategizing with the client on which solution should be implemented, which problem should be solved [5]. As a result, many engineers are not involved in the decision making and problem defining processes and are not required to consider the broader impact of what of for whom they are designing. Kolko suggests that empathy, which he believes can be both taught and learned, is imperative for the creation of user-friendly products, and that successful design requires the integration of human factors and an empathy with the users [11].

Opinion can be held without accountability or understanding, but empathy requires the designer to give up their opinions and egos in order to truly immerse themselves in another's world [4]. We have been exploring potential approaches that could encourage the distanced worlds of human factors and technical engineering to come together. This work is based on the research behind the conceptualization of a tool to increase the ability of engineering students to observe and empathize with those for whom they will be designing, and by doing so, increase the human factors incorporated in their design projects.

\subsection{Research Projects}

After an initial design project, it was clear that encouragement and intentions were not enough to integrate empathetic principles into engineering design. A client came to the author with a specified problem, the design of a science center exhibit to teach the principle difference between potential and kinetic energy types. Despite the desire of the designers to include human factors and user experience considerations, most of the research focused on the users as the only stakeholders of interest within the design project. Within that research, the understanding of the users was done purely through observation which allowed the knowledge to be filtered through the engineering lens in which the designer was trained. The project was ill-timed, but due to a lack of investigation by the designer into the problem landscape and the justifications behind the project, this was not discovered until far too late in the project.

It was expected that a designer who was conscientious about incorporating experiential learning would lead to a usable and desirable exhibit which would benefit the science center. However, even though the designer produced a workable prototype as a solution and human factors were researched and considered, the project did not achieve success. The exhibit was eliminated from the new plans for the science center and the prototype now resides abandoned in an engineering lab.

Our research also included a case study to identify the source of human consideration in a capstone design project. The students produced a product which included human factors, satisfied the client, and which was graded highly by their peers and instructors. However, once we started investigating the source of the human factors in this design project, we found that many of them were provided by the client in the project requirements. The team was convinced early in the process by the client of the value of the project as stated, and they did not see a need to question his thorough justifications. The requirements were met, but the 
validation processes indicated that the team did not fully understand the reasons behind the inclusions. Based on evaluations of their documentation and logbooks, as well as speaking with the team and the client, we do not believe that the team would have been inclined to include the human considerations had the client not so thoroughly required and integrated them into the success of the project.

This research has resulted in the idea that a tool was needed to help novice designers introduce human factors into the early stages of their design process. Even wellintentioned engineers are swept into the mindset that requirements are the only priority of the design and can quickly forget the human centered aspect in the midst of specifications and technicalities. Instead of fighting this, we believe that integrating a consideration of humans as a requirement will allow the engineering designer to use their inclinations towards a successful design, while keeping the human factors from being added at the end. It was clear to us that there needed to be a tool to allow for an external prompting of these considerations, a way to monitor and require its use, and a way to make it portable and easy to access by the students.

\section{APP DEVELOPMENT}

It was in this consideration of different platforms that could influence and help novice designers that the idea of a mobile application, or app, was created.

\subsection{Tool Choice}

Due to the prevalence of smart phones and personal computers, we believed that a mobile application would be a familiar way to reach designers, both students and professionals, on a platform in which they were comfortable interacting and to which they had high accessibility. Constructivist Theory of Learning suggests that learning is increased when the user is engaged, with relevant material, and a choice of interactivity [21]. Even in 2006, before the rise of the prominence of smartphones and related apps, $97 \%$ of North American Medical schools using online course material [9]. Mobile applications have been used in a variety of industrial sectors and across other facets of society. The Braille Institute has created an app titled VisionSim to help those with healthy vision to understand how the world appears to people experiencing nine degenerative eye diseases. Professionals such as veterinarians are also served by apps, as shown by a drug-index app that allows them to access information in a convenient way even during the rushed schedule found in a hospital [15]. We believe that, by redesigning how content is used and delivered to students, we will change the way they approach and progress through their design projects. Like other educational apps, potential benefits of this platform include increased accessibility through the portability, which gives convenient access to relevant project processes.

\subsection{Tool Format}

From the author's experience, engineers are comfortable with the idea of questions and processes that they must work through, which led us to believe that prompting them with questions would be received well. Due to the volume of work which has been done on design processes, usability, and human factors, it is not possible to present students with all, or even most, of the research which has been done in this area without a cognitive overload and subsequent overlooking of the information present. By presenting specific, but open-ended questions for them to answer, with options to guide them towards the sources of more information, we hope to avoid the informational apathy that can result from an excess of information and having to sort through the information themselves.

This results in the possibility that the students will not delve into subjects not broached by the application, and any non-highlighted areas have the possibility of being completely ignored. To avoid this, we will include links to further information, as well as make the suggestions a combination of prompts towards deeper discovery and open-ended questions designed to encourage exploration as opposed to 'correct' or 'right' answers. We avoided making a checklist which could be completed with no real consideration for the user, as no understanding or confirmation of compliance would be necessary in a question statement that are able to be answered with either yes or no.

\subsection{Tool Content}

There is more than one facet of interaction between humans and the technology they use. These include physical, psychological, social, organizational, and political levels which are not independent of one another [19]. By providing a framework requiring students to consider and integrate these factors both at the beginning and throughout their design process, we believe that their designs will be more successful as they take these into account. The content of the app reflects these varying levels, as questions will be directed at each of these. One of the criticisms heard is that engineers often do not understand how to properly integrate their designed technology into the broader system which includes these levels of human interaction [12]. 
The majority of questions and surveys that are currently available to students are based off of validated usability studies, which the students can use once they have a prototype. However, this does not allow them to design with human factors integrated from the beginning, but to only see retro-actively once there is already something designed. While validated, reliable usability surveys are available, such as the System Usability Scale [3], these are often evaluated at the end of the process as opposed to an integration from the beginning of the human factors. We believe that incorporating these empathic considerations as requirements before there is a prototype or even a defined problem will allow the engineer to understand better the world of design that they are stereotypically excluded from.

Designers now must consider how their solutions can benefit and interact with the user, where humans are placed at the center of the design process and system [7]. We then, require the students to identify the major stakeholders- those involved in the use, benefit, manufacture, repair, disposal- of the design. By identifying how their design fits into the larger social and organizational levels, they are more aware of the different roles played by people throughout the life of their project. If purely physical or anthropometric research is performed, it may be that entire user populations will be missed, such as nurses when working on a medical device. The goal of human-centered and empathic design is that the goals and preferences of the stakeholders will be considered and a solution will be found which benefits and aligns to these stakeholders [2].

In order to create a system of checks and points of discussion, the app is going to require that the students insert their answers, thought processes, and justifications for different points in their process. Because we have seen that requiring aspects works better as a motivator than simply recommending them, by requiring the answers to the human factor promptings, we believe the students will adopt the processes more readily than they would if we only made it available to them as an optional tool. In order to see that it is being used, there needs to be a deliverable that can be handed in with other required documentation. For this reason, we include a method for the answers of the students to be saved, exported, and handed in as proof of compliance. Their answers, research, and justifications can be reviewed and critiqued with the ability to check from the beginning of their design process which human aspects they have considered.

\subsection{CONCLUSION}

Through our investigation into how engineers incorporate different facts of design into their process, we found that they are very highly motivated by their sets of requirements. In order for them to consider human factors, we need to create a tool that would be mandatory from the beginning in order to make a difference to their design process. By creating an app that prompts the designer with questions and requires them to gain an understanding of the needs and desires of other people we believe we will increase their empathy for both users and other members of the design process.

As we move forward, we wish to create a validated model of which questions and which prompts to give the students. As the problems they are working on are inherently messy and broad, we also will work on identifying areas where the questions can be informative and helpful without being too narrow in scope. This tool is meant to be a framework and a guide as opposed to a strict path for the designers to follow. Identifying how this required feedback changes the design process of students is also of interest for future iterations of the tool.

Design, and the process of designing, has said to be above all else, the difference between an engineering education and a science education [6]. By creating a tool which fits into the engineering design process and pushes them to understand the human factors, we believe we will push the students beyond unusable and undesirable projects, and help guide them to successful, humancentered projects.

\section{Acknowledgements}

The authors gratefully acknowledge the financial support of the Natural Sciences and Engineering Research Council of Canada (NSERC).

\section{References}

[1] Adams, J. L. (2012). Good products, bad products: essential elements to achieving superior quality. McGraw-Hill.

[2] Battarbee, K., Suri, J. F., \& Howard, S. G. (2014, January 9). Empathy on the Edge. Retrieved February 14, 2015, from http://www.ideo.com/images/uploads/news/pdfs/Empa thy_on_the_Edge.pdf

[3] Brooke, J. (1986). SUS - A Quick and Dirty Usability Scale. Reading, UK: Digital Equipment Co Ltd. Retrieved from http://cui.unige.ch/isi/icle-wiki/_media/ipm:testsuschapt.pdf

[4] Bullard, B. (2007). Commencement Speech. San Francisco University High School. 
[5] Design Industry Advisory Committee. (2004). Design Matters: DIAC Design Industry Study Final Report. Ontario: Design Industry Advisory Committee.

[6] Hodge, B., \& Steele, W. (1995). Experiences with a Curriculum with Balanced Design Content in All Stems. ASEE Annual Conference Proceedings.

[7] IDEO. (2009). Human-Centered Design Toolkit. Retrieved February 16, 2015, from http://www.ideo.com/images/uploads/hcd_toolkit/IDE O_HCD_ToolKit.pdf

[8] Jones, J. C. (1992). Design Methods (2nd ed.). New York, NY: John Wiley \& Sons.

[9] Kamin, C., Souza, K., Heestand, D., Moses, A., \& O'sullivan, P. (2006). Educational Technology Infrastructure and Services in North American Medical Schools. Academic Medicine, 81(7), 632-637.

[10] Kolawole, E. (2015, April 9). Empathy. (Stanford University d.school) Retrieved April 22, 2015, from http://www.designkit.org/mindsets/4

[11] Kolko, J. (2014). Well Designed: How to Use Empathy to Create Products People Love. Boston: Harvard Business Review Press.

[12] Kozey, J. (2015, April 14). Associate Professor, School of Health and Human Performance.

[13] Lima, M., \& Oakes, W. (2006). Service Learning: Engineering in your Community. Okemos, MI: Great Lakes Press.

[14] Muster, D., \& Mistree, F. (1989). Engineering Design as it Moves from an Art towards a Science: Its impact on the Education Process. International Journal of Applied Engineering Education, 5(2), 239-246.
[15] i.PEI (2013, August). Timless Veterinary Systems Inc. Launches Mobile Drug Formulary App. (Innovation and Technology Association of Prince Edward Island) Retrieved February 2, 2015, from http://itap.ca/timeless-veterinary-systems-inclaunches-mobile-drug-formulary-app/

[16] Petroski, H. (2006). Success through Failure- the paradox of design. Princeton, New Jersey: Princeton University Press.

[17] Simon, H. A. (1982). The Sciences of the Artificial (2nd ed.). Cambridge, MA: The MIT Press.

[18] The Royal Academy of Engineering. (2005, February). Resources for Lecturers- Educating Engineers in Design. Retrieved January 12, 2015, from http://www.raeng.org.uk/education/highereducation/education-programmes

[19] Vincente, K. J. (2003). The human factor: revolutionaizing the way people live with technology. Toronto: Alfred A Knopf Canada.

[20] Vinodrai, T. (2009). The Place of Design: Exploring Ontario's Design Economy. Toronto, ON: Martin Prosperity Institute.

[21] Wilson, B. G. (1996). Constructivist Learning Environments: Case Studies in Instructional Design. Englewood Cliffs, New Jersey: Educational Technology Publications, Inc. . 